\title{
El artista profesor en el ámbito escolar de la enseñanza artística. Propuestas expresivas vs. Interdisciplinarias
}

\author{
Lila Nemirovsky (U.P.M)
}

\section{Resumen}

En el presente trabajo nos planteamos las posibilidades didácticas que excedan el límite de lo meramente expresivo para dejar lugar a propuestas de arte interdisciplinares en el ámbito de la enseñanza escolar. Suponemos que el artista profesor primeramente es artista en nuestro imaginario colectivo, nos encontramos con aquel que juega con sus manos, explora su imaginación, hace uso de sus sentidos y ejecuta sus ideas, en papel, lienzo, yeso, telas o cualquier medio plástico que permita la representación de aquello con lo que desea expresar. Porque en nuestro imaginario, el artista tiene la profunda necesidad de expresar y hacer visible su imaginación. En este sentido nos olvidamos del arte que no es netamente expresivo como eje central y presenta propuestas vinculadas a materias tangenciales como la física, la química, el deseo inconsciente y la actuación, entre otros.
\end{abstract}

Palabras - clave

Educación artística; interdisciplinaridad; proceso creativo; arte; educación

\section{Comencemos preguntándonos}

¿Qué se espera entonces del artista profesor en el marco escolar de enseñanza de las artes visuales?

En nuestro imaginario social se espera muchas veces que el artista -convertido en profesor- enseñe artes visuales cuyo fin creativo se manifieste en el resultado inmediato del alumno, alentándolo a una producción expresiva y muchas veces sin dar demasiado lugar hacia otras funciones enraizadas del arte que bien podrían ser aprovechadas y enseñadas de modo de ir conformando tal como mencionado previamente, un proceso creativo flexible e interdisciplinar que pueda también ser aplicado en otros contextos

¿O acaso el artista tuvo tradicionalmente a la expresión como fin único del arte?

No se trata aquí de proponer una suerte de programación artística meramente académica respecto a la enseñanza de las artes visuales en el contexto escolar sino de mirar más allá de la proposición simplemente artesanal-expresiva en cuanto a las artes en el colegio se refieren y sugerir quizás un camino que se nutra también de la enseñanza de la historia del arte de forma simultánea a la proposición de las variadas técnicas artísticas, alternando

$$
=12=
$$

ISSN: 2447-1267 Santa Catarina, v.5, n.1, ano 3, março de 2017. 
instrucción con expresión, de manera de ir construyendo un proceso creativo cuyos pilares encuentren en la historia del arte fuentes de inspiración que contribuyan a la creación artística interdisciplinar y que tienda a contribuir con la resolución de problemáticas que se presenten a lo largo de la vida. Conformando así un proceso creativo que pueda aplicarse a otros contextos y situaciones independientemente de la expresión visual.

Quisiera proponer algunos ejemplos de la historia del arte donde observamos las diversas funciones de la creación artística, no siempre vinculada con la expresión personal. Es que tal como sostenía E. H. Gombrich, "cuanto más retrocedemos en la historia, mas definidos pero también más extraños, son esos fines a los cuales el arte tenía que servir" ${ }^{1}$

Si abandonamos nuestros países civilizados para viajar por aquellos cuyos modos de vida conservan todavía semejanza con las condiciones en las cuales vivieron nuestros remotos antepasados, nos daremos cuenta que no existe diferencia entre la construcción útil y la creación de imagen, en cuanto a necesidad concierne. Sus chozas están ahí para resguardarle de la lluvia, el viento, el sol y también de los espíritus. Porque las imágenes están hechas para protegerlos contra otras fuerzas que son tan reales como la naturaleza. Pinturas y esculturas son empleadas con fines mágicos (Gombrich). Es así como estas ideas pueden ayudarnos a entender la finalidad artística del hombre prehistórico, cuyas pinturas al ser descubiertas por los arqueólogos en cuevas de España y al sur de Francia en el sigloXIX, no podían creer que estuvieran hechas por los hombres del periodo glaciar.

\footnotetext{
"Una cosa está clara y es que nadie se arrastraría dentro de las profundidades de una montaña solamente para decorar un lugar tan inaccesible. Incluso más, vemos que pocas de estas pinturas se distribuyen con claridad por los techos o las paredes de la cueva excepto algunas pinturas de la cueva de Lascaux. " ${ }^{2}$
}

\footnotetext{
1 Gombrich plantea en su libro La historia del arte que el sentido del arte variaba según las necesidades coyunturales y culturales de cada época, presentando una diversidad de funciones artísticas según la época histórica que estudiemos.

2 Ramírez Juan Antonio en su libro, Arte pre-histórico y primitivo, nos comenta sobre el sentido que podría llegar a tener el hecho de haber pintado las escenas en las profundidades interiores de las cavernas del hombre glaciar, preguntándose si acaso la distribución de las pinturas afectaría el sentido de la obra.
}

$$
=13=
$$




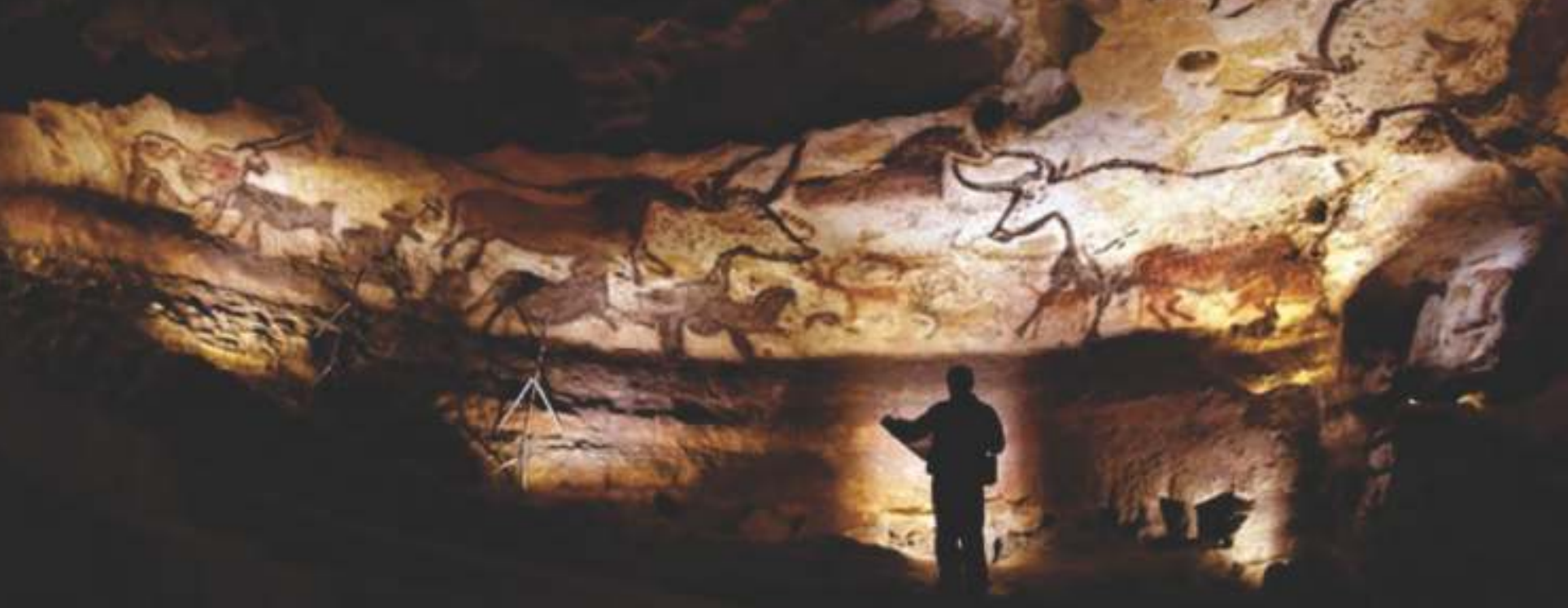

Figura 1. Cueva de Lascaux, Francia 15.000 - 10.000 a.C

Las pinturas están colocadas allí confusamente, una por encima de la otra. Resulta entonces verosímil creer que fueran parte de la creencia universal reinante en aquel entonces bajo la cual con el sólo hecho de pintar a sus presas, los verdaderos animales sucumbirían al poder del hombre.

En este mismo camino observamos la representación de manos en algunas cuevas de la Cordillera de Los Andes, como en la cueva del arroyo Pedregoso, en la Patagonia chilena, por mencionar sólo un ejemplo, en los que se han encontrado hartas pinturas de manos en positivo y negativo.

"La mano inmóvil y ficticia de la cueva no agarra ni atrapa y sin embargo procrea; la mano de piedra no trabaja y caza y sin embargo produce y crea; la mano abstraída de la mano concreta no lucha ni manda y sin embargo impera; la mano pintada e impresa no sanciona ni castiga y sin embargo santifica" ${ }^{3}$

${ }^{3}$ César Romeo en su libro, La mano y la máscara, evoca poéticamente el sentido de la mano en las cuevas patagónicas argentinas, y expande su idea hacia el resto de las cuevas rupestres, explicando cómo la mano está ligada a la representación y simbolismo.

$$
=14=
$$


En síntesis la mano se revela a la comunidad como lo sagrado y está presente a lo largo de los años en el arte rupestre, siendo que la diferencia de materialidad -carne o piedra - no es esencial. ${ }^{4}$

De esta forma vemos que la necesidad artística no pasa por la mera expresión personal sino que se da bajo un proceso simbólico cargado de creencias mágicas en los poderes que iban más allá de la propia ilustración física para convertirse en una suerte de talismán, plasmado en las cuevas que ciertamente rendiría sus frutos en la vida cotidiana.

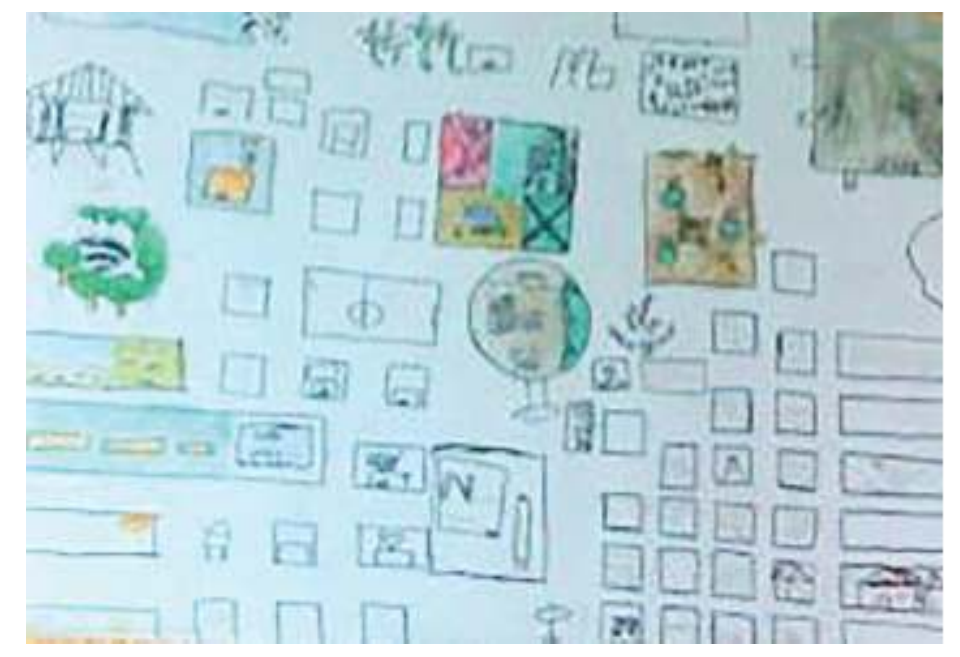

Figura 2. Proceso simbólico-creativo en la elaboración del mapeamento de una ciudad ideal realizada por alumnos de $4^{\circ}$ año de Fundamental I.

Es así como el deseo de alcanzar aquello que está afuera es sintetizado en esto que está adentro de la cueva, que bien podríamos interpretar como la propia cabeza del hombre glaciar, mostrando por ejemplo diversos animales y formas de caza. El proceso tiene aquí más que ver con el deseo de alcanzar un objetivo y dentro de este proceso se inscriben las formas y los pasos a seguir como si se tratara de una suerte de organigrama para cumplir. De esta manera, la idea de proceso expresado simbólicamente, en el campo de arte glaciar podría introducirse y por qué no traducirse a propuestas artísticas en sala de aula que contribuirán sin duda a la capacidad de aplicar procesos en otros campos de la vida.

Si nos remontamos ahora al periodo Medieval, vemos como "La

\footnotetext{
"María Mercedes Podestá, Rodolfo A. Raffino, Rafael Sebastián Pauneroy Diana S. Rolandi en su publicación sobre El Arte rupestre de Argentina indígena: Patagonia, enfocan con precisión que la materia carece de importancia al tratarse de un arte simbólico.
}

$$
=15=
$$


pintura era para los iletrados lo mismo que la escritura para aquellos que saben leer ${ }^{\prime 5}$

Ya hemos visto que nuestra moderna noción de que un artista debe ser creativo, innovador y original no fue en modo alguno compartido por la mayoría de los pueblos del pasado. Ningún artista medieval europeo habría comprendido por qué tendría que crear nuevos modos de planear una iglesia, dibujar un cáliz o representar escenas de la historia sagrada cuando tan bien habrían servido a tal propósito los modos antiguos.

El donante que deseaba dedicar un nuevo altar a una reliquia sagrada de un santo patrón, no solo intentaba procurarse los materiales más preciosos que se hallaban a su alcance, sino que también intentaba suministrar al maestro que ejecutaría la obra, algún modelo de cómo debía ser interpretada la leyenda del santo y la producción del altar.

De esta forma vemos que los artistas medievales no se proponían crear una imagen convincente de la naturaleza o realizar obras bajo la estética de belleza expresiva que esperamos ver en las obras actuales, sino que deseaban comunicar a sus hermanos en la fe, el contenido y el mensaje de la historia sagrada, al mismo tiempo que pretendían enseñarla a aquellos imposibilitados de acceder a la lectura de los textos.

La imagen a continuación pertenece al Libro de los evangelios que fue ilustrado en Alemania alrededor del año 1000

Representando el incidente relatado en el evangelio, cuando Cristo lava los pies a sus discípulos tras la última cena:

Le dice Pedro: "No me lavarás los pies jamás" y Jesús le respondió: "Si no te los lavo, no tienes lugar conmigo" y le dice Simón a Pedro: "No sólo los pies sino hasta las manos y la cabeza"

\footnotetext{
"Esta conversación era lo único que importaba para el artista. Representar la habitación en donde la escena tenía lugar resultaba irrelevante para él e incluso podría ser que desviase la atención del significado interno del
}

\footnotetext{
${ }^{5}$ Cita del Papa Gregorio I (n. Roma; c. 540 - m. 12 de marzo de 604), llamado Magno por sus importantes escritos teológicos, fue el sexagésimo cuarto papa de la Iglesia católica (desde el 3 de septiembre de 590 hasta su muerte) y primer monje en alcanzar la dignidad pontificia.
}

${ }^{6}$ Evangelio de Juan 13, 1-15

$=16=$

ISSN: 2447-1267 Santa Catarina, v.5, n.1, ano 3, março de 2017. 


\section{APOTHEKE}

EST ÚD I O D E

P I N T URA

acontecimiento. En cambio situó las principales figuras contra un fondo dorado, luminoso y plano, sobre el que los gestos de los protagonistas resaltan como si se tratara de una inscripción solemne: la actitud implorante de San Pedro y el gesto calmo con el que Cristo imparte su enseñanza. A la derecha uno de sus discípulos se saca las sandalias mientras otro acerca un recipiente, los restantes se apiñan detrás de San Pedro. " ${ }^{7}$

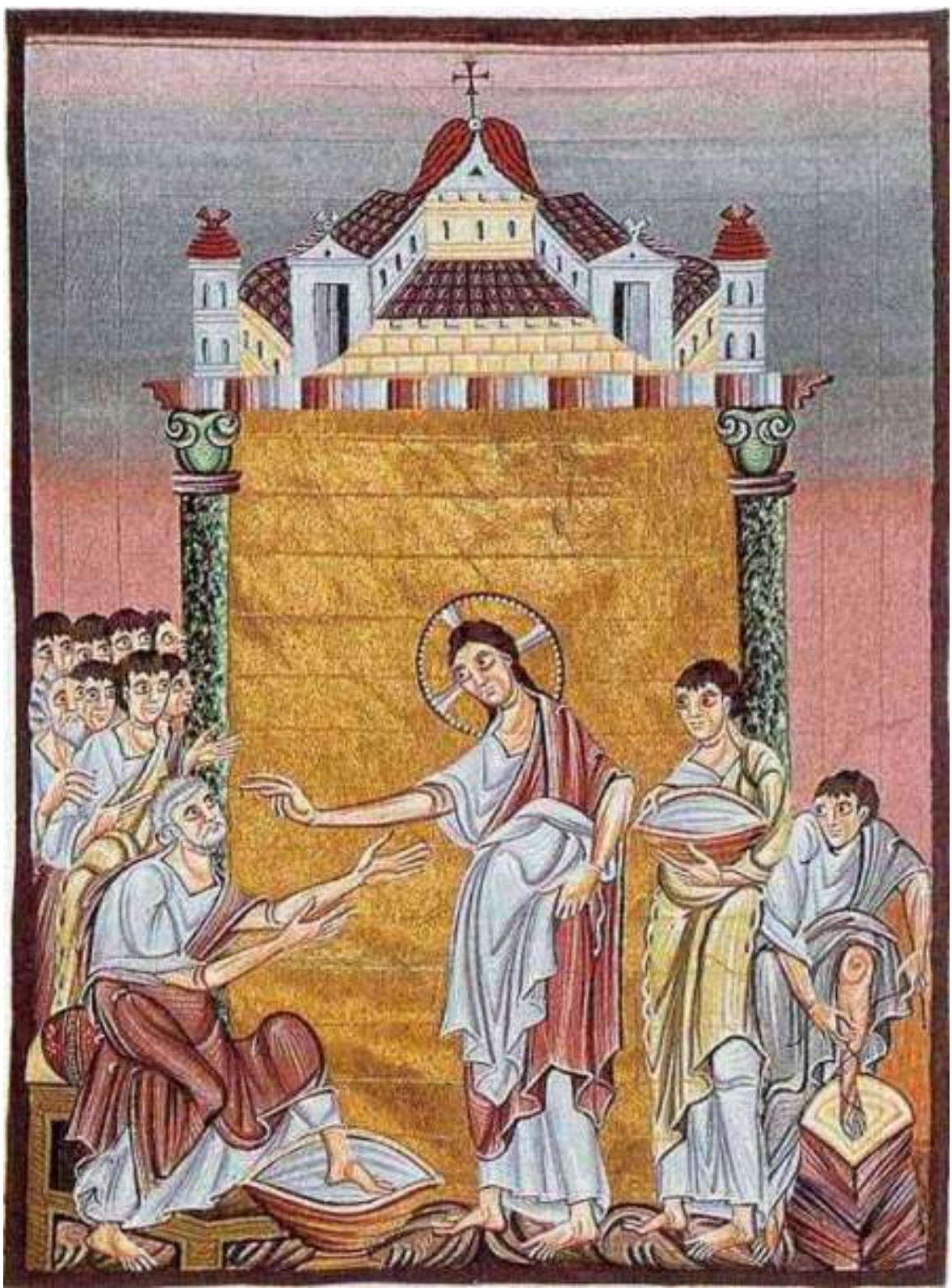

Figura 3. Ilustración del Libro de los apóstoles. Aprox. Año 1000. Alemania

El historiador André Grabar nos explica en su libro, Las vías de la creación en la icnografía Cristiana, que el eje principal en la pintura medieval tiene que ver prácticamente con el ideal de comunicación del texto sagrado, sin adicionar "adornos" que distraerían la atención del espectador.

$$
=17=
$$


Observamos que todas las miradas se dirigen hacia el centro de la escena con cierta rigidez, dándonos la sensación de que allí está sucediendo algo de suma importancia. La expresión aquí es pues el contenido comunicado, que nada tiene que ver con los propios sentimientos del artista creador.

Vemos pues que en efecto la experiencia de la belleza inteligible constituía una realidad moral y psicológica para el hombre de la edad media y la cultura de la época no quedaría suficientemente iluminada si se pasara por alto este factor. Los medievales elaboraban al mismo tiempo, mediante analogía, por paralelos explícitos o implícitos, una serie de opiniones sobre la belleza sensible, la belleza sobre las cosas de la naturaleza y el arte. Efectivamente, el campo de interés estético de los medievales era bastante más amplio que el nuestro y su atención hacia la belleza de las cosas a menudo estaba estimulada como la conciencia de la belleza como dato metafísico.

Los medievales, al desconfiar de la belleza exterior, se refugiaban en la contemplación de las escrituras o en el goce de los ritmos interiores de un alma en estado de gracia. No tenían una religión de la belleza separada de una religión de la vida, si lo bello era un valor debía coincidir con lo bueno, lo verdadero y demás atributos del ser y la divinidad.

En esta misma línea nos comenta Gombrich que

\footnotetext{
"Lo importante para el artista era transmitir el mensaje de los textos sagrados y que éste sea comprensible para una gran mayoría de espectadores. De esta forma la belleza exterior no resulta ser el objetivo principal del artista sino que el interés primario radica en transmitir un mensaje revelador a modo de belleza interior. ${ }^{8}$
}

El arte es pues comunicación de aquello que es bello, bueno y verdadero y la importancia de la transmisión de las ideas se vuelve uno de los ejes principales de la época medieval.

\footnotetext{
${ }^{8}$ Gombrich, en su libro, La historia del arte, explica cómo en la pintura medieval la mayor importancia se situaba en la pura comunicación de los textos sagrados hacia aquellos que se veían imposibilitados de poder comprenderla de otro modo. De esta forma se revelaba una suerte de belleza interior de la pintura, dejando a un lado aquello que resultaba superficial o de "belleza exterior".
}

$$
=18=
$$


Transmitir y traducir las artes medievales al ámbito escolar, podría ayudar en la realización de actividades donde ilustraciones basadas en textos consigan transmitir un mensaje claro y específico, contribuyendo de esta manera a la elaboración de procesos conceptuales en la lectura, la capacidad de síntesis y el desarrollo de representación de textos. En definitiva un texto resumido en imágenes logra convertirse en un excelente esquema, incluso mental para recordar relatos en la posteridad.

No se trata de introducir las artes medievales con el fin de copiar la acción de gráfica del artista medieval. Sino por el contrario, resulta ser un claro ejemplo de transmisión y traducción de textos -en aquel caso sagrados- para la comprensión final del relato a través de las imágenes visuales.

La idea de enseñar este tipo de ejemplos históricos vinculados con la actividad plástica escolar, resalta la importancia de vincular la imagen visual con la comunicación escrita y permite desarrollar la capacidad de comprensión de texto al mismo tiempo que desenvuelve una potente capacidad de síntesis en el alumno.

Particularmente, en el transcurso de los años como profesora de artes visuales en una escuela particular y bilingüe de la ciudad de San Pablo, Brasil tuve el placer de poder sugerir diferentes textos a mis alumnos en función de sus edades. Cuentos cortos de Franz Kafka, Italo Calvino, Hans Christian Andersen o fabulas de La Fontain, entre otros, fueron parte del repertorio propuesto a los alumnos de entre 8 y 13 años. Los textos, mayoritariamente en ingles debido al carácter bilingüe de la institución, fueron leídos, subrayados, resumidos, prácticamente desmembrados y sintetizados en pocas palabras bajo un ejercicio de comunicación visual a imágenes únicas que pudieran resumir el contenido general del relato, eligiendo y destacando aquello que fuera de mayor importancia. De esta forma, el proceso creativo se construía resaltando la síntesis de la comprensión de texto en una imagen ilustrada donde el trazo y el color constituían las partes libradas al azar muchas veces explotadas en el conjunto visual.

$$
=19=
$$




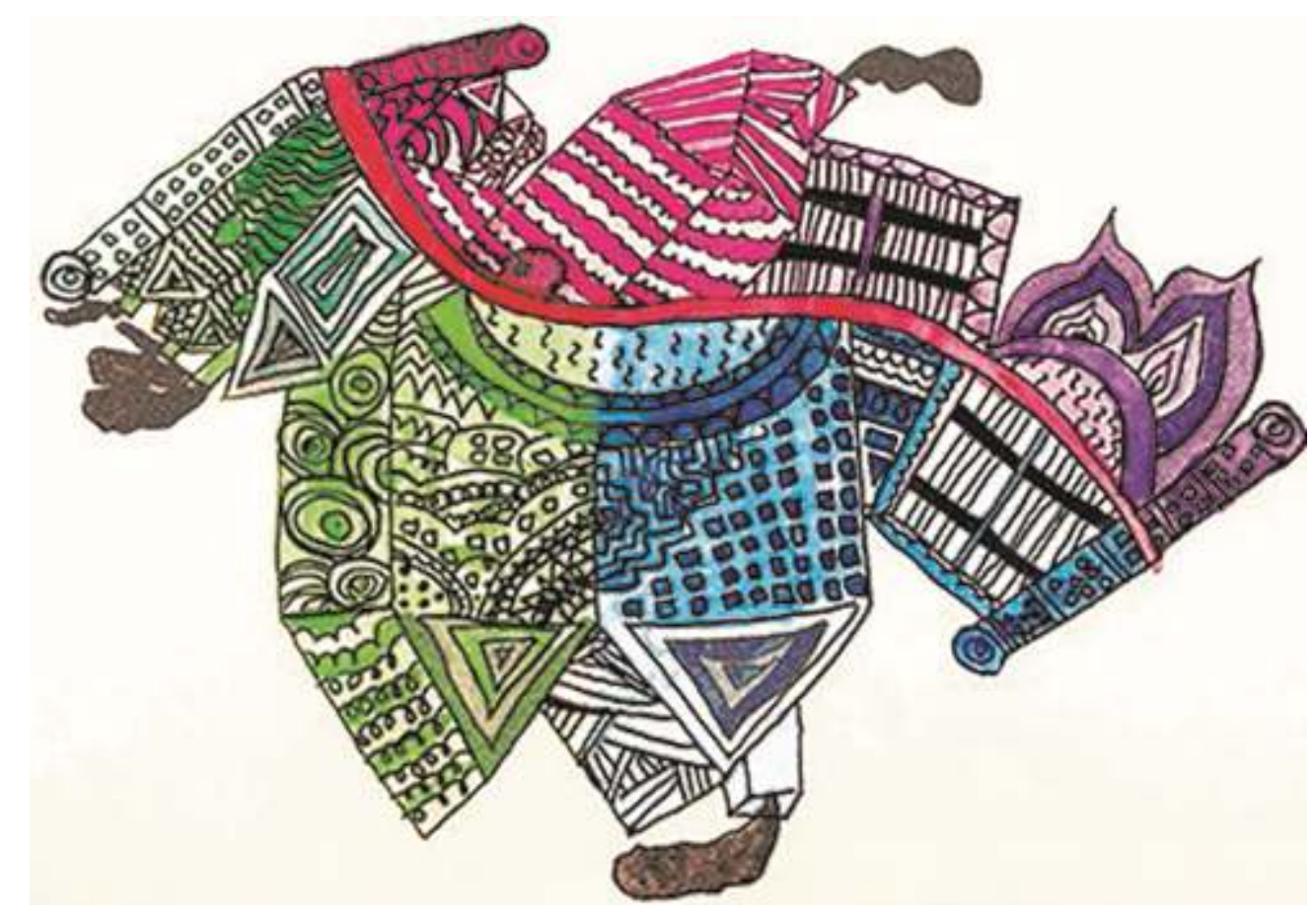

Figura 4. Síntesis visual realizada por alumna de $7^{\circ}$ año basado en el texto Ciudades invisibles I de Italo Calvino.

Una vez más volvemos a preguntarnos si el artista tuvo tradicionalmente a la expresión como fin único del arte y si los profesores de educación artística deberíamos proponer únicamente actividades donde el proceso expresivo sea el predominante.

¿O acaso no podríamos contribuir a la construcción visual con procesos que involucren la interdisciplinaridad junto a otros campos tales como por ejemplo la física y la incidencia de la fotografía?

Observemos ahora el caso de los pos impresionistas como Georges seurat quien empleando los métodos pictóricos impresionistas, estudió la teoría científica de la visión cromática y decidió construir sus cuadros mediante minúsculos puntos uniformes de colores puros como si se tratara de un mosaico, confiando que con éstos se mezclarían en la retina de quien mirase.

Estos colores puros y primarios que yuxtapuestos evitando mezclarse, son combinados en la retina de quien observa, conforma la tonalidad deseada por el autor, pudiendo ésta variar según la distancia que se deje. Es así como la imagen puntillista pasa a tener continuidad como si hubiera sido pintada por líneas en lugar de puntos. 

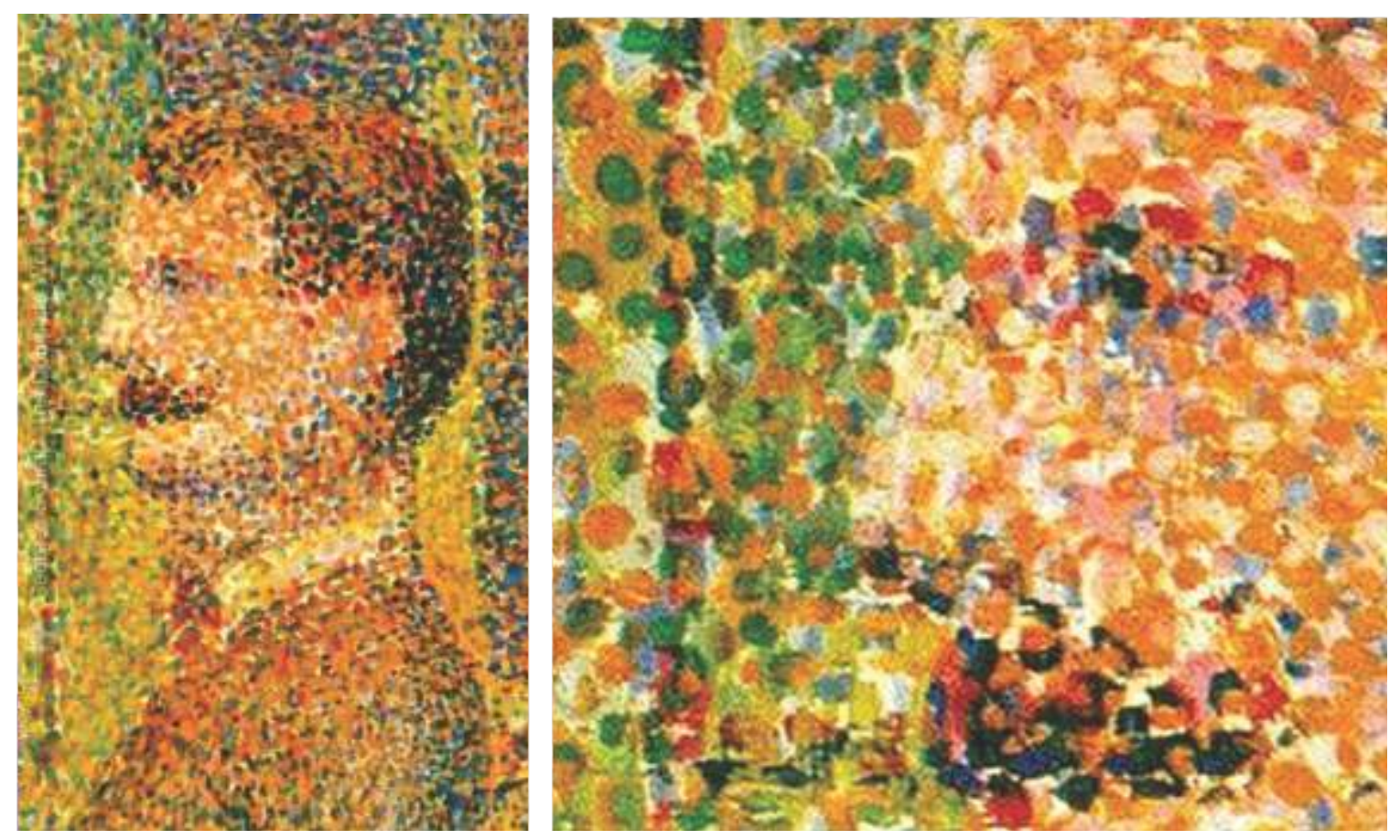

Figura 5. La Parade, Seurat 1889

\begin{abstract}
"Las teorías de seurat procedían de sus lecturas de los textos estéticos y científicos del siglo XIX sobre el color y de esta forma podemos afirmar que la tonalidad ideada por el artista no se encontraba en el cuadro pintado sino en la mente de quien observaba, como si se tratase de una ilusión óptica que se genera en la retina o mejor aún en la mente. Es el cuadro construido en la mente, como si se tratara de una nueva aparición de arte conceptual del siglo $\mathrm{xX}$ aunque anticipándose un siglo. ${ }^{9}$
\end{abstract}

Esta misma ejercitación de ciencia y arte trae aparejada una serie de desarrollos en los procesos creativos que bien podrían llevarse a cabo en sala de aula. No se trata de acotar sino de acrecentar la búsqueda en campos incluso aparentemente ajenos al arte, de modo de ampliar la capacidad creativa, cognitiva e incluso expresiva del alumno. Llevando la materia artística hacia un área interdisciplinar de pensamiento múltiple donde la reflexión, la observación y el proceso creativo integren el dinamismo de la disciplina.

\footnotetext{
${ }^{9}$ Valero Muñoz Antonio, en su libro, Principios e Luz y holopintura, nos comenta sobre los efectos físicos de las pinturas post impresionistas, rescatando que la pintura en su totalidad se forma en la mente de quien la observa ya que los colores -pequeños puntos de color puro- se reciben en la retina y es el cerebro quien termina descifrándolos, estableciendo una imagen global.
}

$$
=21=
$$


¿Qué ocurre cuando el fin único del artista es la pura expresión individual?

Tomemos el ejemplo de Jackson Pollock, quien ya en 1947 había creado el estilo que lo había hecho famoso: abstracciones libres e informales basadas en una técnica de goteo y manchas sobre el lienzo, cuyo ejemplo podemos ver a continuación

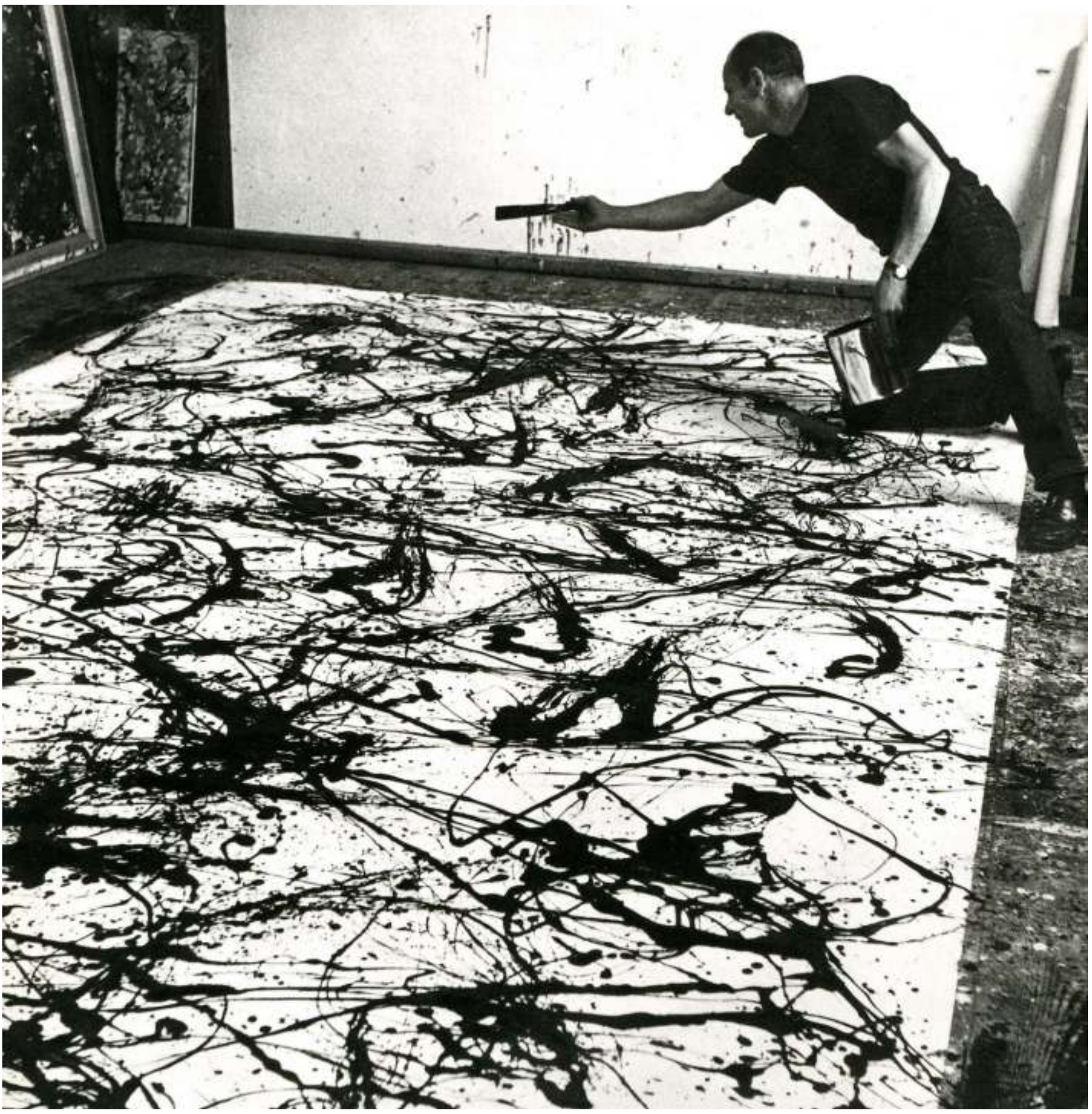

Figura 6. Jackson Pollock en su atelier de East Hampton, New York 


\section{가으.}

Non 5 440204

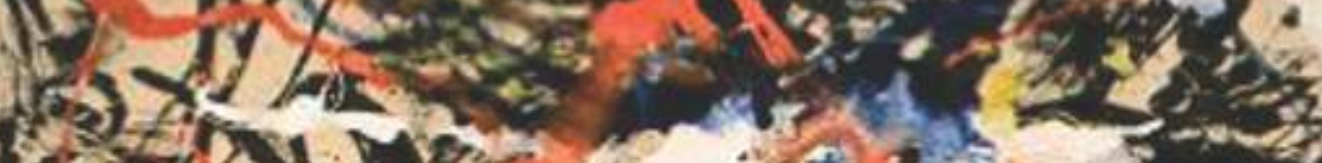
$52)^{7}=5$ ond 7 cortands (a) 3

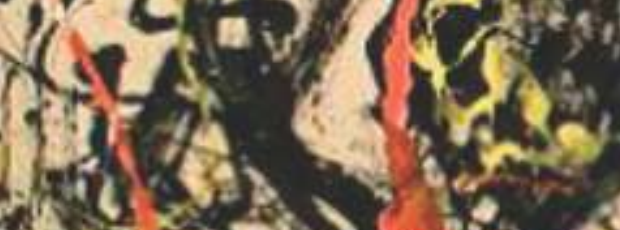
I. $, 1,121$

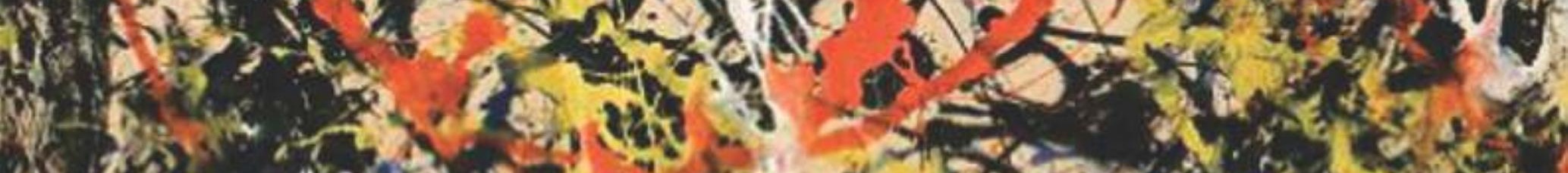
131 - $15 \mathrm{~K}$ 닌 sen 4 . 24

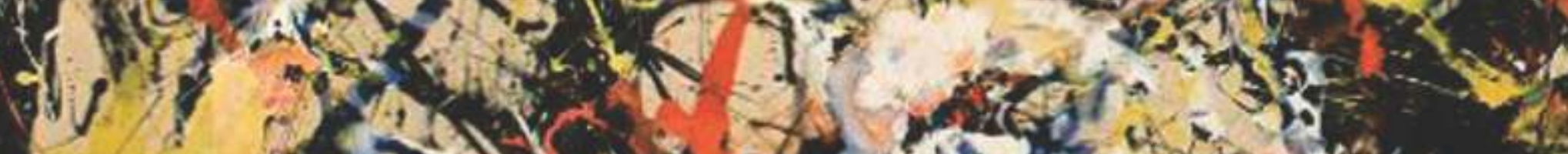

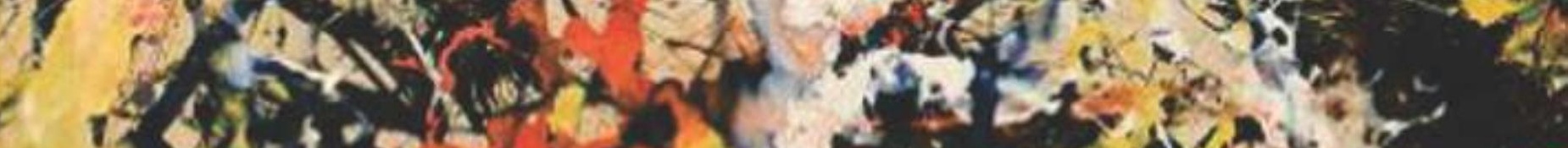

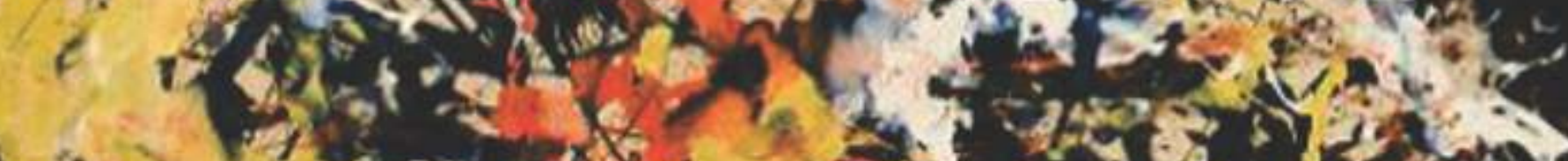
th

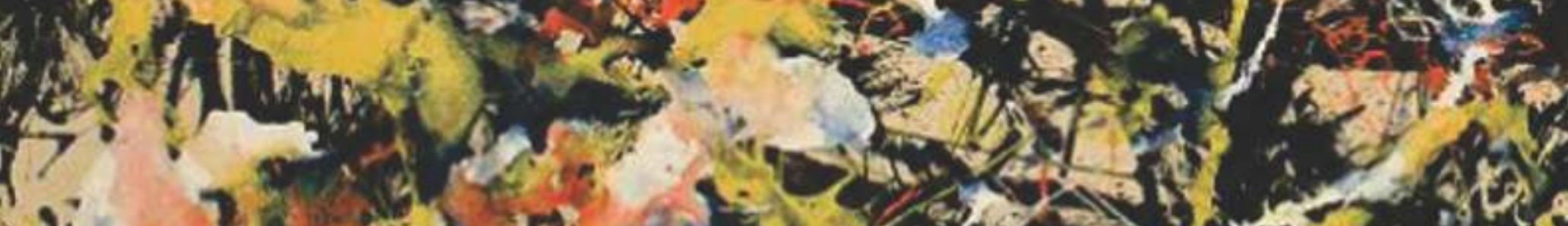

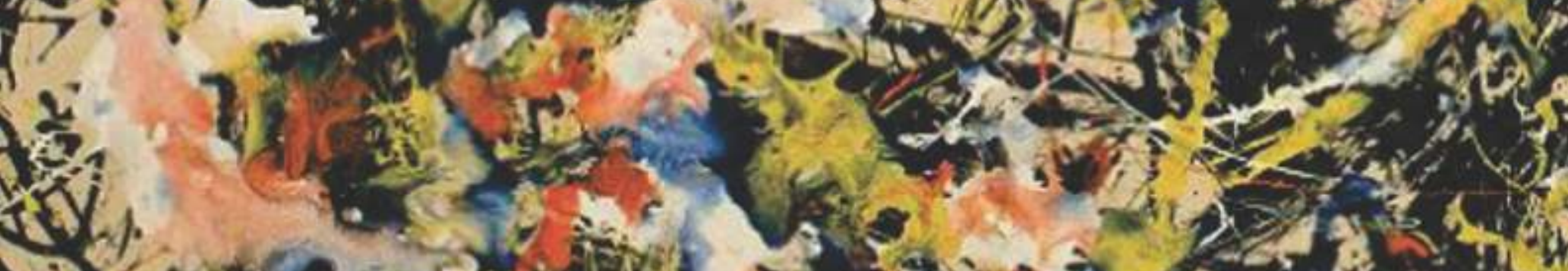

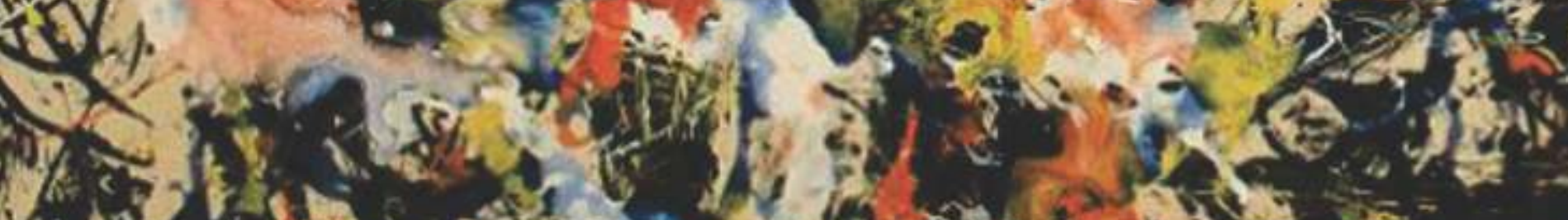

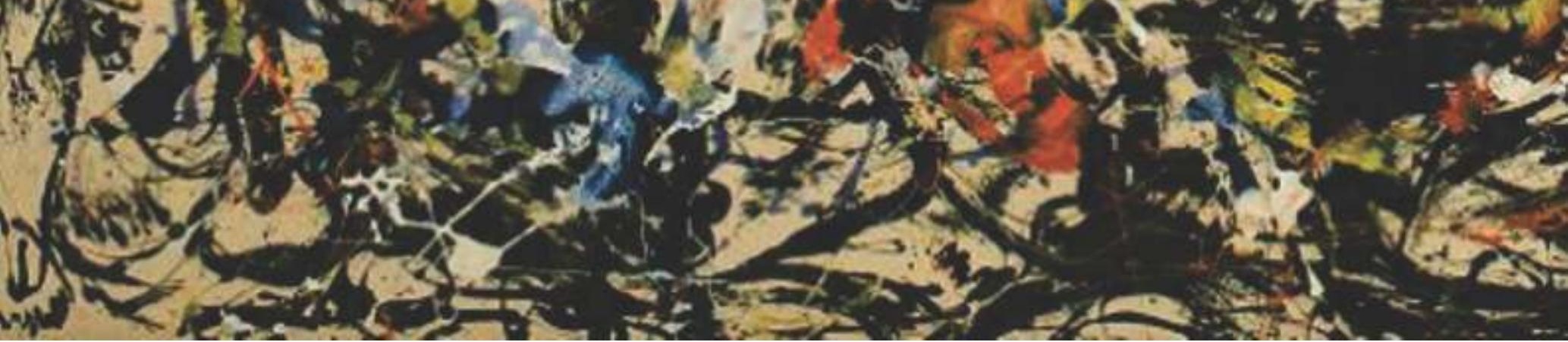




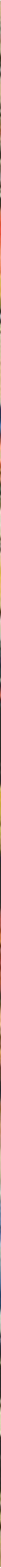


1943 por los tres artistas expresionistas: Mark Rothko, Adolf Gottlieb y Jackson Pollock sostenían que entre sus preferencias artísticas se encontraban los grandes lienzos y un punto de vista enfocado en el arte como si se tratara de "una aventura hacia un mundo desconocido" ${ }^{12}$

De esta manera y citando al coleccionista y crítico de arte Samuel Kootz vemos que "La combinación americana de pura abstracción y expresividad en el pincel, gritaba realmente algo nuevo"13 como si se tratara de una puesta en escena, "el lienzo parecía un escenario en donde actuar, antes de ser un espacio para reproducir ${ }^{\prime 14}$ se trataba pues de un espacio dedicado exclusivamente a la expresión espontanea desvinculada de cualquier condicionamiento, convirtiendo el proceso creativo era exclusivamente un proceso de auto-conocimiento.

Es así como la vinculación de los casos que hemos venido viendo entre arte y deseo -en el caso del arte rupestre- arte y comunicación -como hemos visto en el arte medieval eclesiásticoarte vinculado a las teorías de la física -como hemos analizado en el post impresionismo- e incluso en el arte expresivo de los expresionistas abstractos, conforman un universo artístico interdisciplinar nutrido de un campo tangencial que excede teóricamente el campo del arte y que sin embargo lo nutre en forma constante, contribuyendo por qué no al desarrollo inteligible que bien podría aplicarse en sala de aula de forma de conseguir la interacción de varias disciplinas cuyo denominador común resulte en la producción artística, esta vez con un background de información que conlleve a la profundización de la materia.

\footnotetext{
Harold Rosenberg comenta en sus escritos que la ejecución de lo que él llamó de Expresionismo abstracto está estrechamente vinculado con el acto de lanzarse al vacío en lo que depararía en una aventura hacia lo desconocido.

${ }^{3}$ El coleccionista y galerista Samuel M. Kootz quien a principios de la década del 40’se encontraba en búsqueda de un nuevo tipo de arte, resumía de esta forma la genial originalidad que él veía en los nuevos expresionistas americanos.

14 Nuevamente el crítico y escritor Harold Rosenberg, define a los expresionistas abstractos americanos como artistas de la acción en una suerte de arena o escenario donde a través de la catarsis de su interpretación, encontraban el vínculo efectivo con la expresión gráfica.

$$
=25=
$$
}




\section{APOTHEKE}

ESTUDIO DE

P I N T URA

\section{Referências}

ALONSO TEJADA, Anna; GRIMAL Alexandre. Introducción al Arte levantino a través de una estación singular: la Cueva de la Vieja. 1.ed. Albacete: Revista Dialnet, 1999.

CHAREAU, P; CAGE, J; ROSENBERG, H. Possibilities 1: an occasional review. New York: Editorial George Wittenborn, 1947.

ECO, Umberto. Arte y belleza en la estética medieval. 1.ed. Barcelona: Editorial Lumen, 1997.

FREEDBERG, David. El poder de las imágenes. Madrid: Ediciones Cátedra, 1992.

GOMBRICH, E.H. La historia del arte. Londres: Editorial Phaidon, 2009.

GRABAR, André. Las vías de la creación en la iconografía cristiana. 4.ed. Madrid: Editorial Alianza Forma, 1994.

KERR, Houston. An introduction to art criticism. 1.ed. Maryland: Maryland Institute College of Arte - Editorial Pearsons, 2013.

KOOTZ, Samuel. New Frontiers in American Painting. New York: Literary Licensing, 2012 .

LUCIE-SMITH, Edward. Movimientos artísticos desde 1945. 4.ed. Barcelona: Ediciones destino, 1995.

PAUNERO, Rafael Sebastián, PODESTÁ, María Mercedes. El arte rupestre de Argentina indígena: Patagonia. Buenos Aires: Boletín de la Academia Nacional de Historia, 2005.

RAMÍREZ, Juan Antonio. Arte prehistórico y primitivo. Madrid: Editorial Anaya, 1989 .

ROMEO, César. La mano y la máscara, Meditación sobre un motivo del arte rupestre patagónico. Buenos Aires: Edición del Cuaderno Patagónico, 1984.

ROSENBERG, Harold. Art on the edge: creators and situations. Chicago: The University of Chicago Press, 1975.

VALERO MUÑOZ, Antonio. Principios e Luz y holopintura. Alicante: Editorial Club universitario, 2013. 
Lila Nemirovsky, nascida em Buenos Aires, Argentina.

Mestranda do curso de Pós-graduação na Universidade Presbiteriana Mackenzie.

Bacharel em História da Arte, Universidade Autónoma de Madri, Espanha, cujo diploma foi homologado pela Universidade do Estado do Rio de Janeiro.

Especialização em Design e Produção de vidro, Instituição Vetroricerca, Bolzano, Itália. Recebendo o prêmio de Bolsa integral de estudos do FSE para a totalidade da especialização de 2 anos.

É professora de Artes visuais -em inglês- na escola bilíngue Aubrick de São Paulo.

Trabalhou em Venezia, Holanda e Finlândia sempre no campo do design e do vidro.

Fez exposições em Bolzano, Barcelona, Madrid, Turku e Buenos Aires. Foi convidada como palestrante da Bienal do Design de Chile 2010 e desde o 2012 mora em São Paulo.

http://lattes.cnpq.br/8269952145343993 